\title{
KONFLIK AGAMA DAN PENYELESAIAANNYA: Kasus Ahmadiyah di Kabupaten Tasikmalaya, Jawa Barat
}

\author{
Muhamad Zuldin \\ Fakultas Ilmu Sosial dan Politik UIN Sunan Gunung Djati \\ Jl. A.H. Nasution 105 Cibiru, Bandung, 40614 \\ e-mail:muhammadzuldin@yahoo.com
}

\begin{abstract}
Abstrak: Tulisan ini bertujuan untuk menyelidiki faktor-faktor penyebab konflik antara Islam mainstream dengan Ahmadiyah, resolusi konfliknya, peran SKB Tiga Menteri tahun 2008 dan Pergub tahun 2011 sebagai media resolusi konflik, dan respons terhadap SKB dan Pergub. Dalam tulisan ini ditemukan bahwa faktor-faktor penyebab konflik bermula dari aspek teologis, kemudian berkembang menjadi aspek politik, ekonomi, sosial, ketidaktegasan pemerintah, Ahmadiyah eklusif dalam beribadah, dan pengaruh pemberitaan media massa. Resolusi konflik berupa non litigasi dilakukan melalui mediasi yang melibatkan aparat pemerintah, tokoh masyarakat, kepolisian, dan litigasi melalui proses peradilan. Ahmadiyah menganggap SKB dan Pergub tidak bisa berperan sebagai media resolusi konflik agama sehingga mereka menolak serta berusaha membatalkannya secara hukum. Sebaliknya, Islam mainstream menerima namun tetap menginginkan keluarnya Keppres atau Undang-Undang untuk membubarkan Ahmadiyah.
\end{abstract}

\begin{abstract}
Religious Conflict and Its Resolution: A Sutdy of Ahmadiyah in Tasikmalaya, Weste Java. This writing is aimed at analyzing factors that underly conflicts between mainstream Islam and Ahmadiya, its resolution, the role of SKB Tiga Menteri of 2008 and Pergub 2011 as a media of conflict resolution, as well as the responese to the two statutes. The findings of this study reveal that the religious conflicts stem from theological aspects that extend to political, socio-economic, government's inambiguity in implementing the regulation, Ahmadiya's exclusiveness in their religious duties and the influence of media. Conflict resolution in non-litigation is carried out through mediation that involving the goverment's apparatus and the police, and litigation via judicial process. Ahmadiya argues that SKB and Pergub are incapable of playing any role in resolving religious conflict and thus reject and try to revoke them judicially. Mainstream Islam, however, argues to the opposite and insists in issuance of President Act or statute to disperse Ahmadiya organization.
\end{abstract}

Kata Kunci: konflik agama, Ahmadiyah, SKB, Pergub, Tasikmalaya 


\section{Pendahuluan}

Jemaat Ahmadiyah adalah nama ajaran dan gerakan yang yang ditokohi oleh Mirza Ghulam Ahmad (1839-1908) di Qodian, Punjab, India. Ajaran dan gerakan ini oleh kalangan Muslim Sunni Ortodoks, dianggap menyimpang dari ajaran Islam sebenarnya. Ajaranajaran Ahmadiyah yang umumnya dianggap menyimpang adalah, terutama, mengenai tiga hal, yaitu penyaliban Nabi 'Isa a.s., al-Mahdi yang dijanjikan akan muncul di akhir zaman, dan tentang penghapusan kewajiban berjihad. ${ }^{1}$ Ajaran Ahmadiyah ini, tidak hanya ditolak oleh mayoritas Muslim, tetapi juga oleh komunitas Kristen dan Hindu. Hal itu disebabkan karena disamping mengklaim dirinya sebagai Nabi, Mirza Ghulam Ahmad juga sebagai al-Masih yang dijanjikan, penjelmaan Nabi 'Isa, yang merupakan konsep dalam Kristen. Sedangkan dalam Hindu, Mirza menganggap dirinya sebagai avatar (kendaraan) dari Krisna. Pengklaiman itu pada awalnya ditujukan untuk merespons situasi pluralisme agama yang sedang berkembang di India pada saat itu. ${ }^{2}$

Penyebaran Ahmadiyah ke daerah Tasikmalaya bermula dari ditugaskannya Entoy Mohammad Tayyib yang berasal dari Singaparna oleh M. Rahmat Ali pada akhir 1934 untuk melakukan dakwah Ahmadiyah di daerah Jawa Barat, khususnya daerah Priangan (Bandung, Sumedang, Cianjur, Garut, Tasikmalaya, dan Ciamis). Tasikmalaya adalah tempat pertama yang dikunjungi oleh Entoy Mohammad Tayyib. ${ }^{3}$

Pada masa-masa awal penyebarannya, Ahmadiyah telah mendapat penentangan dari masyarakat dan beberapa ulama setempat. Penentangan pada saat itu baru berupa perdebatan teologis yang berkisar tentang kenabian Mirza Ghulam Ahmad. Meskipun penentangan masyarakat terhadap Jemaat Ahmadiyah tidak pernah padam, organisasi ini masih tetap eksis. Bahkan secara nasional, keberadaan Jemaat Ahmadiyah di Indonesia sebagai suatu organisasi telah diakui oleh pemerintah Indonesia sebagai badan hukum dengan Penetapan Menteri Kehakiman Republik Indonesia tanggal 13 Maret 1953 No.J.A.5/23/13. ${ }^{4}$

Pada masa pemerintahan Soeharto, Majelis Ulama Indonesia (MUI) mengeluarkan fatwa sesat terhadap Jemaat Ahmadiyah pada tahun 1980. Fatwa MUI ini gemanya tidak seberapa dan respons umat pun tidak banyak. Hal ini disebabkan oleh pemerintahan Soeharto h. vii.

${ }^{1}$ Muhammad Iqbal, Islam dan Ahmadiyah, terj. Machnun Husain (Jakarta: Bumi Restu, 1991),

${ }^{2}$ William Montgomery Watt, Islamic Fundamentalism and Modernity (London and New York: Routledge, 1988), h. 58-59.

${ }^{3}$ Kunto Sofianto, "Gerakan Jemaat Ahmadiyah Indonesia di Jawa Barat, 1931-2000: Penyebaran Ideologi dan Respons Masyarakat, 2011” (Tesis: Universiti Kebangsaan Malaysia, 2011), h. 88-92.

${ }^{4}$ Munasir Sidik, Dasar-Dasar Hukum \& Legalitas Jemaat Ahmadiyah (Jakarta: Jemaat Ahmadiyah Indonesia, 2008). h. 21; Fawzy Sa'ied Thaha, Ahmadiyah dalam Persoalan (Bandung: Al-Ma'arif, 1981), h. 361. 
yang sedang berkuasa pada saat itu sangat represif yang mengutamakan ketertiban dan kurang tahunya masyarakat tentang fatwa MUI tersebut. ${ }^{5}$

Pada masa Reformasi, MUI mengeluarkan fatwa kembali pada 2005. Fatwa ini menguatkan kembali fatwa sebelumnya dengan tambahan agar pemerintah berkewajiban membubarkan aliran Jemaat Ahmadiyah. Pada masa ini, terjadi penentangan yang luar biasa terhadap keberadaan Ahmadiyah, khususnya setelah bermunculan ormas-ormas Islam garis keras. Konflik antara Jemaat Ahmadiyah dengan Islam mainstream ${ }^{6}$ tidak terhindarkan dan terjadi di beberapa tempat seperti Jakarta, Bogor, Cianjur, Garut dan Tasikmalaya.

Untuk menghindari konflik dan kekerasan lebih lanjut, pemerintah pusat dan daerah telah mengeluarkan beberapa peraturan berupa SKB (Keputusan Bersama) Tiga Menteri tahun 2008 dan Pergub (Peraturan Gubernur) tahun 2011. Meskipun beberapa peraturan telah dikeluarkan, konflik Jemaat Ahmadiyah dengan Islam mainstream masih juga terjadi. Masalah penelitian ini adalah sebagai berikut. Pertama, faktor-faktor apa saja yang menyebabkan konflik antara Ahmadiyah dengan kelompok Islam mainstream di Kabupaten Tasikmalaya, Jawa Barat? Kedua, bagaimana resolusi konflik antara Ahmadiyah dengan kelompok Islam mainstream di Kabupaten Tasikmalaya, Jawa Barat? Ketiga, Apakah SKB Tiga Menteri tahun 2008 dan Pergub tahun 2011 dapat dijadikan media untuk meresolusi konflik antara Islam mainstream dengan Ahmadiyah? Keempat, Bagaimana pandangan Ahmadiyah dan Islam mainstream terhadap SKB Tiga Menteri tahun 2008 dan Pergub tahun 2011 ?

\section{Metode Penelitian}

Metode penelitian yang digunakan adalah metode kualitatiffenomenologi dengan

${ }^{5}$ Di tingkat Internasional, para ulama yang tergabung di Liga Muslim Dunia (Rabithah Alam Islâmî) telah melangsungkan konferensi tahunannya di Makkah Saudi Arabia dari tanggal 14 s/d 18 Rabiul Awwal 1394 H (6 s/d 10 April 1974) yang diikuti oleh 140 delegasi negaranegara Muslim dan organisasi Muslim dari seluruh dunia juga telah menfatwakan sesat terhadap aliran ini dan menganggap berada di luar Islam. Fatwa MUI tahun 1980 ini keluar di samping ada tuntutan dari masyarakat juga mendapat pengaruh fatwa dari Rabithah 'Alam Islâmî. negara tetangga, seperti Malaysia dan Brunai Darusalam, juga telah melarang keberadaan Jemaat Ahmadiyah di wilayah teritorial mereka. Namun demikian, keberadaan mereka di negara-negara tersebut masih tetap eksis.

${ }^{6}$ Istilah mainstream menurut Van Bruneissen, secara sosiologis disebut juga ortodoksi yang bukan merupakan konsep yang mutlak, namun relatif dan dinamis. Dikatakan mainstream karena paham ini-dalam hal ini faham Ahli Sunah Waljamaah-dianut oleh mayoritas umat Islam Indonesia berdasarkan preferensi sebagian besar ulama atau lebih tepatnya golongan ulama yang dominan. Kelompok ini menjadi mapan ketika mendapat dukungan politik dari penguasa, sehingga kelompok lain yang tidak disetujui dicap sesat. Pengaruh mainstream, menurut Azyumardi Azra, dapat dilihat perannya sebagai bagian dari civil society yang bermain dalam high politics yang mengambil peran politik dalam pemerintahan, turut memengaruhi proses pengambilan keputusan politik. Lihat Dewi Nurrul Maliki, "Resistensi Kelompok Minoritas Keagamaan Jemaat Ahmadiyah Indonesia," dalam JSP: Jurnal Ilmu Sosial dan Ilmu Politik: Multikulturalisme dan Pergulatan Identitas, Vol. XIV, No 1, Juli 2010. 
model naturalistik. Data primer diperoleh dari para informan (pelaku, tokoh ormas Islam, tokoh Ahmadiyah, para birokrat, dan grassroot). Informan penelitian ini ditentukan secara purposif, dengan menggunakan teknik snowball sampling. Sedangkan data sekunder dalam penelitian ini didapat dengan melakukan analisis dokumen administrasi di kantor-kantor pemerintah, dokumen berbagai instansi, laporan penelitian, jurnal penelitian, majalah, surat kabar dan buku teks. Pengumpulan data dalam penelitian ini dilakukan dengan observasi terlibat (participant observation) dan wawancara mendalam (in depth interview) dengan para informan.

\section{Konflik Agama}

Penelitian ini berangkat dari teori konflik klasik Karl Marx dan teori konflik kontemporer, yang diwakili oleh dua mazhab, yakni mazhab Positivistik (Ralp Dahrendorf dan Lewis Coser) dan mazhab Humanis (Herbert Blumer dan Peter L. Berger). Karl Marx berpendapat bahwa konflik terjadi dalam sepanjang sejarah manusia karena faktor determinasi ekonomi. Sedangkan Dahrendorf berpendapat bahwa konflik terjadi karena faktor perebutan wewenang dan kekuasaan. Menurutnya, ada dua macam kelompok konflik, yaitu kelompok laten dan manifest. Kelompok laten tidak terlibat langsung dalam peristiwa konflik, sedangkan kelompok manifest terlibat langsung. Herbert Blumer mengatakan bahwa konflik dapat terjadi karena perbedaan dalam menafsirkan simbol-simbol. Berger berpandangan bahwa konflik dapat terjadi karena pembenaran terhadap realitas sosialnya.

Konflik dibagi ke dalam dua tipe dasar konflik, yaitu konflik realistis dan konflik non realistis. Konflik realistis memiliki sumber yang kongkrit atau bersifat material, seperti perebutan sumber ekonomi atau wilayah. Jika mereka telah memperoleh sumber rebutan itu, dan bila dapat diperoleh tanpa perkelahian, maka konflik akan segera diatasi dengan baik. Konflik non realistis didorong keinginan yang tidak rasional dan cenderung bersifat ideologis, seperti konflik agama dan etnis. Antara konflik pertama dan kedua, konflik non realistis cenderung sulit untuk menemukan resolusi konflik. Sangat memungkinkan bahwa konflik melahirkan kedua tipe ini sekaligus sehingga menghasilkan situasi konflik yang lebih rumit. ${ }^{7}$

Konflik agama dibagi ke dalam empat tipe. Pertama, konflik antara agama dengan ilmu pengetahuan dan budaya, misalnya konflik antara agama dan ilmu pengetahuan yang terjadi pada Abad Pertengahan dalam agama Katholik. Kedua, konflik karena pemanfaatan agama untuk mencapai tujuan tertentu. Dalam konflik jenis ini, agama dijadikan

${ }^{7}$ Lewis Coser, The Functions of Social Conflict (Glencoe, IL: Free Press, 1956), h. 157. Bandingkan dengan Nasikun yang membagi dua macam tingkatan konflik, yaitu konflik ideologis dan konflik politis. Konflik ideologis terwujud dalam bentuk konflik antar sistem nilai yang dianut dan menjadi ideologi dari berbagai kesatuan sosial. Konflik ini mudah disimak di dalam hubungan perbedaan agama dan keyakinan, dan konflik antar suku bangsa. Konflik bersifat politis terjadi dalam bentuk pertentangan di dalam pembagian status kekuasaan dan sumber-sumber ekonomi yang terbatas di masyarakat. Nasikun, Sistem Sosial Indonesia (Jakarta: Rajawali, 1992), h. 63. 
alat untuk mencapai tujuan politik, ekonomi, dan sosial dari pihak-pihak tertentu. Ketiga, konflik di antara para penganut agama yang berbeda. Konflik jenis ini sering menimbulkan konflik fisik dan kekerasan, misalnya Perang Salib yang terjadi hampir tiga ratus tahun antara Islam dan Kristen. Keempat, konflik para penganut satu agama yang terjadi dalam aliranaliran dalam satu agama. Sumber konflik adalah adanya penafsiran yang berbeda mengenai tafsiran kitab suci atau ajaran agama oleh para pemimpin agamanya. ${ }^{8}$

Lebih lanjut, kekerasan agama digolongkan ke dalam tiga tipe. Pertama, kekerasan intern agama. Kekerasan ini biasanya terjadi dalam agama tertentu. Para tokoh agama yang ingin melakukan kritik internal (sebagai usaha pembaharuan atau purifikasi) harus berhadapan dengan kelompok yang menghendaki status quo. Dari sini muncul kecenderungan radikalisme progresif atau radikalisme ortodoks yang berujung pada hubungan kekerasan akibat dari kebuntuan komunikasi dan sikap saling mempertahankan dan menyalahkan pihak lain. Kedua, kekerasan muncul ketika agama memandang dirinya berada di tengahtengah masyarakat yang zalim. Agama mempunyai tuntutan moral untuk melawan dan memberantasnya. Ketiga, kekerasan muncul ketika agama merasa terancam eksistensinya oleh agama-agama lain. Dalam sejarah, ini merupakan kekerasan yang memilukan. ${ }^{9}$

Untuk mengatasi konflik agar tidak menjadi menjadi lebih destruktif, diperlukan campur tangan pihak ketiga yang berperan sebagai safety valve atau katup penyelamat. Dalam hal ini, untuk mengatasi konflik yang bernuansa agama dalam masyarakat Indonesia, diperlukan intervensi pemerintah dengan membuat peraturan dalam rangka meresolusi konflik yang ada supaya tidak menjadi lebih destruktif dan menciptakan hubungan antar pemeluk dan inter pemeluk umat beragama yang lebih konstruktif dan harmonis. Negara berkewajiban menyelesaikan konflik-konflik umat beragama.

Ada dua cara yang umum di dalam penyelesaian konflik yaitu melalui litigasi dan non litigasi, di samping cara-cara yang lainnya. Proses non ligitasi yang sering digunakan adalah negosiasi, mediasi, konsiliasi dan arbitrasi. Sedangkan resolusi konflik litigasi atau peradilan adalah resolusi yang menggunakan proses hukum nasional dan dilakukan di pengadilan. Para pihak yang terlibat dalam konflik kekerasan tersebut diadili menurut ketentuan hukum nasional yang berlaku dan diselengarakan di pengadilan. Biasanya keputusan akan diambil oleh hakim setelah mempertimbangkan bukti-bukti hukum dari kedua pihak yang terlibat dalam suatu konflik itu. ${ }^{10}$

Negara dibangun untuk tujuan mengelola konflik. Pemerintah menjadi aktor penting

${ }^{8}$ Wirawan, Konflik dan Manajemen Konflik: Teori, Aplikasi, dan Penelitian (Jakarta: Salemba Humanika, 2010), h. 72-73.

${ }^{9}$ St. Sunardi, "Keselamatan Kapitalisme Kekerasan," dalam Haqqul Yakin (ed.), Agama dan Kekerasan dalam Transisi Demokrasi di Indonesia (Yogyakarta: eLSAQ Press, 2009) h. 50.

${ }^{10}$ Wijoyo, "Resolusi Litigasi dan Non Litigasi," dalam Yohanes Bahari (ed.), Resolusi Konflik Berbasis Pranata Adat Pamakang dan Pati Nyawa pada Masyarakat Dayak Kanayatn di Kalimantan Barat (Bandung: Program PPS Unpad, 2005), h. 57. 
memelihara iklim harmoni dengan memberikan ruang demokratik bagi para pemeluk agama dan/atau keyakinan apapun. Pemerintah memiliki peran otoritas dalam melakukan kontrol atas berbagai faksi yang ada untuk tujuan memelihara suasana harmonis. ${ }^{11}$ Berbagai kebijakan dan peraturan telah dikeluarkan oleh pemerintah dalam upaya mengatasi konflik umat beragama di Indonesia, seperti SKB, pembentukan FKUB (Forum Kerukunan Umat Beragama), dan Peraturan-peraturan kepala daerah. Berhubungan dengan keluarnya kebijakan dan peraturan tersebut, posisi pemerintah memang sudah memerankan fungsinya, meskipun kebijakan dan peraturan yang telah diambil itu tidak memuaskan semua pihak.

Dalam hal konflik antara Islam mainstream dengan Ahmadiyah, pemerintah baik pusat maupun daerah, telah mengeluarkan kebijakan peraturan-peraturan berupa SKB (Surat Keputusan Bersama) Tiga Menteri Tahun 2008 dan Pergub (Pergub) Tahun 2011 guna mencegah konflik yang lebih besar. Peraturan yang telah dikeluarkan ini mendapat tanggapan yang beragam dari masyarakat.

\section{Hasil dan Pembahasan}

Faktor penyebab konflik antara Islam mainstrem dengan Ahmadiyah di kabupaten Tasikmalaya bermula dari aspek teologis. Kemudian berkembang menjadi aspek politik, ekonomi, eklusivitas, tidak ada tokoh pemersatu dari kedua belah pihak, Jemaat Ahmadiyah eklusif dalam beribadah, tuduhan pelanggaran terhadap SKB dan Pergub, ketahanan masyarakat lokal rendah, pengaruh pemberitaan di media massa tentang konflik antara Ahmadiyah dengan Islam mainstream di daerah lain, dan masyarakat di tataran Sunda, khususnya di kabupaten Tasikmalaya, tidak ditemukan lembaga adat yang berfungsi menyatukan masyarakatnya, selain agama.

Aspek teologi ialah karena terdapat perbedaan pemahaman ajaran dari keduanya. Islam mainstream menganggap tidak ada lagi kenabian, setelah kenabian Nabi Muhammad SAW. Perbedaan ini timbul karena terjadi penafsiran dan pemahaman yang berbeda antar Jemaat Ahmadiyah dengan Islam mainstream. Hal ini, menurut perspektif teori interaksi simbolik, disebabkan karena telah terjadi perbedaan penafsiran dan pemaknaan simbol kata-kata dan ayat -ayat dalam al-Qur'an dan hadis. Pemaknaan terhadap satu simbol yang tidak sama terhadap objek yang sama berpotensi menimbulkan konflik. Perbedaan itu selanjutnya, menurut Herbert Blumer, dikonstruksi ke dalam realitas sosial masingmasing di mana mereka berada dan membentuk doktrin serta pandangan hidup (way of life) yang berbeda. Jemaat Ahmadiyah menganggap doktrin dan pandangan hidupnyalah yang benar (truth claim). Di pihak lain, Islam mainstream menganggap bahwa Jemaat Ahmadiyah telah menodai ajaran Islam yang mereka anut selama ini. Pada awalnya, per-

${ }^{11}$ Thomas R. Dye, Politics in States and Communities (New Jersey: Prentice Hall, Inc., 1988) h. 1., dalam Asep Saeful Muhtadi. Radikalisme Agama: Tinjauan Sosial Politik, Makalah disampaikan dalam diskusi dosen Fakultas Ushuluddin pada tanggal 11 April 2012. 
bedaan ini hanya bersifat polemik saja, namun setelah muncul kelompok-kelompok Islam aliran keras, seperti Front Pembela Islam (FPI), perbedaan doktrin dan pandangan hidup ini mengarah pada konflik kekerasan.

Aspek politik terlihat adanya konflik by design, konflik yang direncanakan untuk kepentingan pihak-pihak tertentu. Konflik antara Jemaat Ahmadiyah dengan Islam mainstream di kabupaten Tasikmalaya sering terjadi pada saat akan ada pemilihan umum (PEMILU), baik tingkat daerah maupun pusat. Konflik dirancang sedemikian rupa untuk tujuan-tujuan politis tertentu, terutama oleh calon kepala daerah. Keberadaaan Jemaat Ahmadiyah di kabupaten Tasikmalaya oleh sebagian besar masyarakat dianggap sebagai stigma umat Islam. Isu ini dimanfaatkan oleh partai-partai yang dalam kampanyenya ingin menghilangkan stigma tersebut, dengan tujuan untuk mendapat simpatik dan dukungan suara pemilih di kabupaten Tasikmalaya. Di samping itu, konflik dan penyerangan terhadap Jemaat Ahmadiyah juga sering terjadi pada saat peringatan hari-hari besar Islam, seperti peringatan tahun baru Islam (1 Muharam) dan menjelang bulan puasa Ramadhan. Kelompok Islam mainstream yang dikomandani oleh aliran Islam garis keras sering melakukan pawai dan arak-arakan menuju perkampungan Ahmadiyah. Tujuannya untuk membuat anggota Ahmadiyah shock therapy sehingga menyadari akan kesesatan ajaran Ahmadiyah. Dalam arakan-arakan tersebut sering terjadi perusakan masjid, rumah, dan simbol-simbol lain milik Ahmadiyah.

Dari aspek ekonomi, ketika terjadi penyerangan dan perusakan tidak jarang terjadi penjarahan harta milik warga Ahmadiyah. Tentu saja tujuan penyerangan dan perusakan milik Ahmadiyah itu bukan untuk menjarah, tetapi sering kali dimanfaatkan oknum-oknum tertentu guna kepentingan pribadi dalam situasi konflik. Secara ekonomi, konflik juga terjadi karena dipicu oleh ketidaksenangan kelompok Islam mainstream kepada Ahmadiyah di salah satu lokasi penambangan pasir di Sukaratu Kabupaten Tasikmalaya. Penambangan itu banyak mempekerjakan dari kalangan Ahmadiyah, sedangkan pekerja dari kelompok Islam mainstrem hanya sedikit. Perusakan juga terjadi di pertokoan dan peternakan domba milik Ahmadiyah. Pihak Islam mainstream bertambah semangat 'menggebuk' Ahmadiyah agar anggaran penanganan masalah Jemaat Ahmadiyah dari Gubernur Jawa Barat dapat dikeluarkan.

Terjadinya konflikjuga disebabkan oleh tuduhan sepihak dari masing-masing kelompok. Pihak Islam mainstream menuduh Ahmadiyah banyak melanggar Surat Keputusan Bersama (SKB) Tiga Menteri tahun 2008 dan Peraturan Gubernur (Pergub) tahun 2011, seperti masih melakukan kegiatan ibadah berjamaah dan merekrut anggota baru. Di pihak lain, Ahmadiyah berketetapan hati bahwa melaksanaan ibadah baik sendiri-sendiri maupun berjamaah merupakan hak asasi yang dilindungi oleh Undang-Undang Dasar 1945.

Potensi konflik juga terjadi karena adanya pelaksanaan program-program sosial dari Ahmadiyah seperti pengobatan gratis dan donor darah untuk warga sekitar. Kegiatan sosial ini seringkali menimbulkan ketidaksenangan bagi kelompok Islam masinstream, 
terutama para elitnya. Mereka mengganggap kegiatan itu hanya sebagai 'kedok' saja untuk merekrut anggota baru Ahmadiyah.

Aspek tidak adanya figur pemersatu bagi kedua pihak, juga memicu terjadinya konflik. Di beberapa tempat di kabupaten Tasikmalaya, seperti Singaparna, Sukaraja, dan Sukaratu, terdapat hubungan keluarga atau hubungan darah antara Islam mainstream dengan Ahmadiyah. Seiring berjalannya waktu, para sesepuh yang dianggap dapat mempersatukan kelompok-kelompok yang bertikai tersebut banyak yang sudah meninggal dunia. Bila terjadi perselisihan antara kedua kelompok tersebut, tidak ada lagi tokoh yang menengahinya, bahkan memicu ke arah yang lebih besar. Sedangkan keturunan-keturunan dari kedua belah pihak, rasa persaudaraan dan kekeluargaannya semakin memudar.

Aspek eklusivitas pihak Ahmadiyah dalam menjalankan ibadah juga memicu terjadinya konflik. Pihak Ahmadiyah tidak mau berbaur dengan Islam mainstream dalam hal beribadah, seperti salat. Keadaan demikian membuat rasa ketidaksenangan di kalangan Islam mainstream. Aspek pemberitaan oleh media massa, khususnya TV (Televisi), yang gencar memberitakan penyerangan terhadap Jemaat Ahmadiyah di berbagai tempat di luar kabupaten Tasikmalaya, juga dapat menstimulus terjadinya konflik kekerasan di beberapa tempat di kabupaten Tasikmalaya. Hal ini berbeda dengan masa pemerintahan Soeharto di mana masyarakat belum banyak yang memiliki Televisi (TV).

Dalam masyarakat Sunda tidak dikenal marga seperti dalam masyarakat Batak. Akibatnya apabila terjadi potensi konflik, tidak bisa diselesaikan secara adat kekeluargaan. Agama adalah satu-satunya faktor pemersatu. Apabila ada pihak luar yang berbeda keyakinan maka timbul rasa persatuan untuk menghadapi keyakinan pihak luar yang berbeda keyakinannya.

Secara umum konflik antara Ahmadiyah dengan Islam mainstream di kabupaten Tasikmalaya banyak terjadi setelah keluarnya fatwa MUI yang kedua pada tahun 2005, dan keluarnya Surat Keputusan Bersama (SKB) Walikota dan Kabupaten Tasikmalaya tahun 2007 bila dibanding dengan keluarnya SKB Tiga Menteri tahun 2008 dan Peraturan Gubernur (Pergub) Jawa Barat tahun 2011. Konflik Islam mainstream dengan Ahmadiyah lebih bersifat laten sedangkan konflik dengan ormas Front Pembela Islam (FPI) bersifat manifest. FPI adalah ormas Islam terdepan dalam menghadapi Ahmadiyah di kabupaten Tasikmalaya.

Resolusi konflik antara Ahmadiyah dengan Islam mainstream di kabupaten Tasikmalaya melalui dua cara, yaitu resolusi konflik non litigasi dan resolusi konflik litigasi. Resolusi konflik non litigasi dilakukan dengan proses mediasi yang melibatkan aparat pemerintah, mulai dari tingkat RT, RW, desa, Muspika, Muspida, dan kepolisian. Pihak FPI melalui intelnya dan laporan masyarakat mendapat informasi tentang kegiatan-kegiatan Jemaat Ahmadiyah yang dianggap melanggar peraturan yang ada. Kemudian minta kepada pemerintah untuk menegur dan memberhentikan kegiatan-kegiatan. Bila pemerintah dan pihak aparat tidak memberhentikan kegiatan Ahmadiyah, maka FPI dan ormas Islam lainnyalah yang turun tangan. Biasanya didahului dengan proses mediasi. Dalam proses ini, sering tidak dicapai 
titik temu karena masing-masing mempertahankan pendapatnya. Akibatnya terjadi tindakan kekerasan terhadap Ahmadiyah berupa perusakan masjid dan aset-aset lainnya. Sedangkan resolusi konflik litigasi dilakukan melalui proses peradilan. Proses ini dilakukan setelah tidak ada kesepakatan dari kedua pihak dan telah memenuhi unsur pidana.

Ahmadiyah menganggap SKB Tiga Menteri tahun 2008 dan Pergub tahun 2011 tidak dapat berfungsi sebagai resolusi konflik. SKB Tiga Menteri tahun 2008 dan Pergub tahun 2011 dianggap merugikan Ahmadiyah. Setelah keluarnya SKB Tiga Menteri tahun 2008 kegiatan Ahmadiyah menjadi sangat terbatas. Apalagi setelah keluarnya Pergub tahun 2011, Ahmadiyah merasa seperti terjepit dan tercekik. Meskipun demikian, Ahmadiyah mengakui SKB Tiga Menteri tahun 2008 dan Pergub tahun 2011 dapat dianggap sebagai jalan tengah yang merupakan resolusi konflik sementara bagi kedua kelompok yang bertikai. Sedangkan Islam mainstream menganggap SKB Tiga Menteri tahun 2008 dan Pergub tahun 2011 dapat dijadikan resolusi konflik dengan beberapa pesyaratan.

Pada umumnya, SKB Tiga Menteri tahun 2008 dan Pergub tahun 2011 di kabupaten Tasikmalaya dapat dijadikan resolusi konflik agama antara Jemaat Ahmadiyah dengan Islam mainstream. Data lapangan menunjukkan bahwa konflik di Kabupaten Tasikmalaya banyak terjadi pada periode tahun 2005-2007 sebelum dikeluarkannya SKB Tiga Menteri tahun 2008 dan Pergub tahun 2011. Setelah dikeluarkannya SKB Tiga Menteri tahun 2008 dan Pergub tahun 2011 angka konflik cenderung menurun.

Islam mainstream tetap menginginkan agar organisasi Ahmadiyah di Indonesia dibubarkan oleh pemerintah dengan menggunakan Keputusan Presiden (Keppres) atau Undang-Undang. Jika tidak dibubarkan, agar Jemaat Ahmadiyah tidak lagi menggunakan nama Islam. Sebaliknya, Jemaat Ahmadiyah tetap berusaha memperjuangkan agar SKB Tiga Menteri tahun 2008 dan Pergub tahun 2011 dapat dibatalkan.

Konflik Ahmadiyah dengan Islam mainstream di kabupaten Tasikmalaya akan terus terjadi, karena konflik yang disebabkan oleh faktor non realistik seperti agama, tidak mudah untuk diselesaikan. Konflik menjadi lebih rumit karena penyebabnya tidak hanya dari faktor non realistik, tetapi juga dari faktor realistik seperti masalah politik dan ekonomi. Peraturan-peraturan yang ada untuk meresolusi konflik antara Jemaat Ahmadiyah dengan Islam mainstream hanya bersifat jalan tengah sementara, yang sewaktu-waktu konflik dapat terulang kembali.

\section{Penutup}

Faktor penyebab konflik antara Islam mainstrem dengan Ahmadiyah di kabupaten Tasikmalaya tidaklah tunggal. Penyebab konflik adalah sebagai berikut. Pertama, Ahmadiyah dianggap telah menistakan keyakinan umat Islam yang sebenarnya. Kedua, isu politik sering dijadikan sebagian masyarakat untuk melakukan tindak kekerasan terhadap Ahmadiyah. Ketiga, Ahmadiyah dianggap sering melanggar SKB dan Pergub. Islam mainstream meng- 
anggap SKB dan Pergub melarang semua kegiatan Ahmadiyah, termasuk kegiatan beribadah. Ahmadiyah menganggap SKB dan Pergub tidak membatasi mereka dalam beribadah. Keempat, pemerintah tidak tegas dalam penerapan hukum. Kelima, ada pihak-pihak luar yang berusaha membenturkan. Keenam, faktor ekonomi. Ketujuh Ahmadiyah eklusif dalam melaksanakan ibadah. Kedelapan, pengaruh pemberitaan media massa tentang konflik di daerah lain, dan para tokoh pemersatu banyak yang sudah meninggal dunia.

Resolusi konflik antara Ahmadiyah dengan Islam mainstream di kabupaten Tasikmalaya melalui resolusi konflik non litigasi yaitu dengan mediasi, dan resolusi konflik litigasi yaitu dengan proses peradilan. Poses mediasi seringkali mengalami jalan buntu, karena masing-masing pihak berpegang pada kebenaran masing-masing. Di beberapa daerah yang jumlah Ahmadiyahnya sangat sedikit, konflik bisa berhenti karena mengalami kelelahan dan Ahmadiyah akhirnya mengalah.

Ahmadiyah menganggap SKB Tiga Menteri tahun 2008 dan Pergub tahun 2011 tidak dapat berfungsi sebagai resolusi konflik. Sedangkan Islam mainstream menganggap sebaliknya dengan beberapa persyaratan. Namun demikian, keduanya menganggap SKB dan Pergub dapat dianggap sebagai resolusi konflik sementara. Berdasarkan jumlah konflik, ditemukan kecenderungan menurun dari tahun ke tahun setelah dikeluarkan SKB Tiga Menteri tahun 2008 dan Pergub tahun 2011.

Islam mainstrem menerima keberadaan SKB Tiga Menteri tahun 2008 dan Pergub tahun 2011 dalam menangani masalah kontemporer terhadap Ahmadiyah tetapi tetap menginginkan Jemaat Ahmadiyah dibubarkan oleh pemerintah dengan menggunakan Keputusan Presiden (Keppres) atau Undang-Undang. Jika tidak dibubarkan, agar Ahmadiyah tidak lagi menggunakan nama Islam. Sedangkan Ahmadiyah menolak keberadaan SKB Tiga Menteri tahun 2008 dan Pergub tahun 2011 dan tetap berusaha memperjuangkan agar SKB Tiga Menteri tahun 2008 dan Pergub tahun 2011 dapat dibatalkan.

Meskipun SKB Tiga Menteri tahun 2008 dan Pergub tahun 2011 hanya bersifat sementara dan masih diperdebatkan, untuk saat ini, SKB Tiga Menteri tahun 2008 dan Pergub tahun 2011 masih bisa dipertahankan di Jawa Barat, khususnya kabupaten Tasikmalaya, guna mengatasi konflik antara Islam mainstream dengan Ahmadiyah. Karena masih terdapat perbedaan penafsiran terhadap SKB Tiga Menteri tahun 2008 dan Pergub tahun 2011, pemerintah daerah diharapkan dapat mensosialisasikannya secara lebih intensif baik di kalangan Islam mainstream maupun Ahmadiyah.

\section{Pustaka Acuan}

Coser, Lewis. The Functions of Social Conflict. Glencoe, IL: Free Press, 1956.

Dye, Thomas R. Politics in States and Communities. New Jersey: Prentice Hall,Inc: 1988. Iqbal, Muhammad. Islam dan Ahmadiyah, terj. Machnun Husain. Jakarta: Bumi Restu. 1991. 
MIQOT Vol. XXXVII No. 2 Juli-Desember 2013

Maliki, Dewi Nurrul. "Resistensi Kelompok Minoritas Keagamaan Jemaat Ahmadiyah Indonesia," dalam JSP: Jurnal Ilmu Sosial dan Ilmu Politik: Multikulturalisme dan Pergulatan Identitas, Vol. XIV, No. 1, Juli 2010.

Muhtadi, Asep Saeful. "Radikalisme Agama: Tinjauan Sosial Politik," Makalah disampaikan dalam diskusi dosen Fakultas Ushuluddin pada tanggal 11 April 2012.

Nasikun. Sistem Sosial Indonesia. Jakarta: Rajawali, 1992.

Sidik, Munasir. Dasar-Dasar Hukum \& Legalitas Jemaat Ahmadiyah. Jakarta: Jemaat Ahmadiyah Indonesia, 2008.

Sofianto, Kunto. "Gerakan Jemaat Ahmadiyah Indonesia di Jawa Barat, 1931-2000: Penyebaran Ideologi dan Respons Masyarakat." Thesis Ph.D: Universiti Kebangsaan Malaysia, 2011.

Thaha, Fawzy Sa'ied. Ahmadiyah dalam Persoalan. Bandung: Al-Ma'arif, 1981.

Yakin, Haqqul. Agama dan Kekerasan dalam Transisi Demokrasi di Indonesia. Yogyakarta: eLSAQ Press, 2009.

Watt, William Montgomery. Islamic Fundamentalism and Modernity. London and New York: Routledge, 1988.

Wijoyo. "Resolusi Litigasi dan Non Litigasi," dalam Yohanes Bahari (ed.), Resolusi Konflik Berbasis Pranata Adat Pamakang dan Pati Nyawa pada Masyarakat Dayak Kanayatn di Kalimantan Barat. Bandung: PPS UNPAD, 2005.

Wirawan. Konflik dan Manajemen Konflik: Teori, Aplikasi, dan Penelitian. Jakarta: Salemba Humanika, 2010. 